\title{
Investigation of patients' access to EHR data via smart apps in Chinese Hospitals
}

\author{
Ting Shu ${ }^{1 \dagger}$, Fan $\mathrm{Xu}^{1 \dagger}$, Hongxia Li $i^{* *}$ and Wei Zhao ${ }^{2^{*}}$ (i)
}

From International Conference on Health Big Data and Artificial Intelligence 2020 Guangzhou, China. 29 October - 1 November 2020

\begin{abstract}
Background: Given that China has encouraged EHR usage in hospitals for more than a decade, patients' access to their own EHR data is still not as widely utilized as expected.

Methods: We cultivated a survey with four categories and field interviews of measures to identify whether hospitals have already released EHR data to patients, inpatients or outpatients, the top EHR release contents and the most popular release software.

Results: Of the 1344 responding hospitals from 30 provinces nationwide, $41.37 \%$ of hospitals have already released their EHR data to patients, of which $97.12 \%$ are through smart apps. More than $91 \%$ of hospitals use WeChat, and $32.37 \%$ of hospitals developed their own standalone apps or use vendors' apps. A total of $54.63 \%$ were released to both outpatients and inpatients, and the top release contents were all objective. A rough estimation is made that releasing EHR data to patients via smart apps may save the hospital 15.9 million RMB per year and patients 9.4 million RMB altogether.
\end{abstract}

Conclusions: EHR data release is believed to bring both patient and hospital cost savings and efficiency gains but is still considered spontaneous and requires legal support and government regulation.

Keywords: EHR data release, Electronic health records, Smart apps, Cost saving, Information security protection

\section{Background}

While electronic health record (EHR) adoption and its use have been reported by hospitals globally [1-5], China has promoted nationwide EHR adoption in hospitals for more than a decade [6-10]. Despite the great progress

\footnotetext{
*Correspondence: ygsxxb@163.com; zw@fuwai.com

${ }^{\dagger}$ Ting Shu and Fan Xu contributed equally to this manuscript 1 Department of Health Care IT, National Institute of Hospital Administration, NHC, Building 3, Yard 6, Shouti South Road, Haidian District, Beijing 100044, China

${ }^{2}$ Department of Information Center, Fuwai Hospital, National Center for Cardiovascular Diseases, Chinese Academy of Medical Sciences and Peking Union Medical College, No.167 North Lishi Road, Xicheng District, Beijing 100037, China
}

in increasing the adoption rate in recent years, patients' access to their own EHR data is still not as convenient as imagined. It is universally known that EHR data compose the core of health care big data today [11-19]. Currently, patient engagement is considered a great way to facilitate patient-centred health care services, and patients' acceptance of their own medical data is the first step, especially through the use of mobile applications, usually smart apps on phones and pads. These trials have been conducted globally, and many countries have cultivated laws, governmental policies, and industrial regulations years ago for legal protection. If EHR data are distributed to patients via smart apps, self-health management, 
patient satisfaction, and health care quality can be greatly enhanced.

The National Health Commission of China (NHC) has published policies to encourage hospitals and small-sized medical facilities to release EHR data to citizens since 2013 [20-25]. In this paper, we report an investigation with survey and field interviews on the actual adoptions, obstacles and cost savings of EHR data release to patients' smart apps and conclude with policy suggestions. Our results provide an important baseline for policymakers to craft regulations for patient access to EHR data.

\section{Materials and methods}

The questionnaire adopted a stratified sampling method. According to the report released by the National Center for Health Statistics at the end of February 2020, there are 2762 tertiary hospitals and 9730 secondary hospitals in China, with a ratio of approximately 1:3.5. According to the same proportion of the number of tertiary and secondary hospitals, a sample survey was conducted. Between August 2019 and October 2019, 1350 questionnaires were collected, including 1050 for secondary hospitals and 300 for tertiary hospitals. Among the received questionnaires, 1344 copies were valid, and 6 responses (all are secondary hospitals) had logic contradiction, which released EHR to patients but filled in "None" in the release software. The total effective rate was $99.56 \%$.

The data in this study were from a specific survey, including basic hospital characteristics (hospital size, hospital type, location in which province), four categories of measures to identify to what degree the hospitals allow patients to access their own EHR data, and in what way do the hospitals release EHR data to patients' smart apps, as detailed below. This survey received responses from 1350 hospitals in China, which covers 30 provinces nationwide. Among these 1344 hospitals, there were 300 tertiary and 1044 secondary hospitals, or 1089 comprehensive and 255 specialized hospitals. The number of hospitals in each province is shown in Table 1.

\section{Results}

\section{Hospital survey}

The primary of all measures is whether a hospital has already released EHR data to patients or not. According to the responses, $41.37 \%$ of hospitals (69\% secondary hospitals and $31 \%$ tertiary hospitals) have already made EHR data accessible to patients; among them, $37 \%$ of secondary hospitals have released EHR, and $58 \%$ of tertiary hospitals have released EHR, of which $97.12 \%$ are through smart apps and only $2.88 \%$ are through traditional format.

Hospitals in China are required to make all of a patient's medical records available to the patient if
Table 1 Responding hospitals in $\mathbf{3 0}$ provinces

\begin{tabular}{|c|c|}
\hline Province & Quantity \\
\hline Anhui & 26 \\
\hline Beijing & 13 \\
\hline Fujian & 22 \\
\hline Gansu & 62 \\
\hline Guangdong & 148 \\
\hline Guangxi & 19 \\
\hline Guizhou & 74 \\
\hline Hebei & 88 \\
\hline Henan & 33 \\
\hline Heilongjiang & 41 \\
\hline Hubei & 44 \\
\hline Hunan & 43 \\
\hline Jilin & 1 \\
\hline Jiangsu & 57 \\
\hline Jiangxi & 33 \\
\hline Liaoning & 48 \\
\hline Inner Mongolia & 16 \\
\hline Ningxia & 19 \\
\hline Qinghai & 6 \\
\hline Shandong & 63 \\
\hline Shanxi & 47 \\
\hline Shaanxi & 57 \\
\hline Shanghai & 24 \\
\hline Sichuan & 96 \\
\hline Tianjin & 18 \\
\hline Xizang & 9 \\
\hline Xinjiang & 5 \\
\hline Yunnan & 122 \\
\hline Zhejiang & 89 \\
\hline Chongqing & 21 \\
\hline
\end{tabular}

requested, according to the "Regulations on prevention and treatment of medical disputes" published in 2018. Therefore, the release of medical records in the traditional format, paper copy, is $100 \%$ for both outpatients and inpatients.

Among the smart apps, the most popular is free WeChat, which was used by more than $91 \%$ of hospitals to release EHR data. Thirty-two percent of hospitals developed their own standalone apps or used vendors' apps, as shown in Fig. 1. Self-service kiosks are often seen in hospitals on-site, with volunteers and nurses helping the patients to operate and print out their records. Other approaches, such as mailing and Compact Disc recording, are also sometimes used.

Hospitals release EHR data of inpatients, outpatients, or both. According to the survey, $42.96 \%$ of responding hospitals released EHR data to outpatients only, 2.41\% 


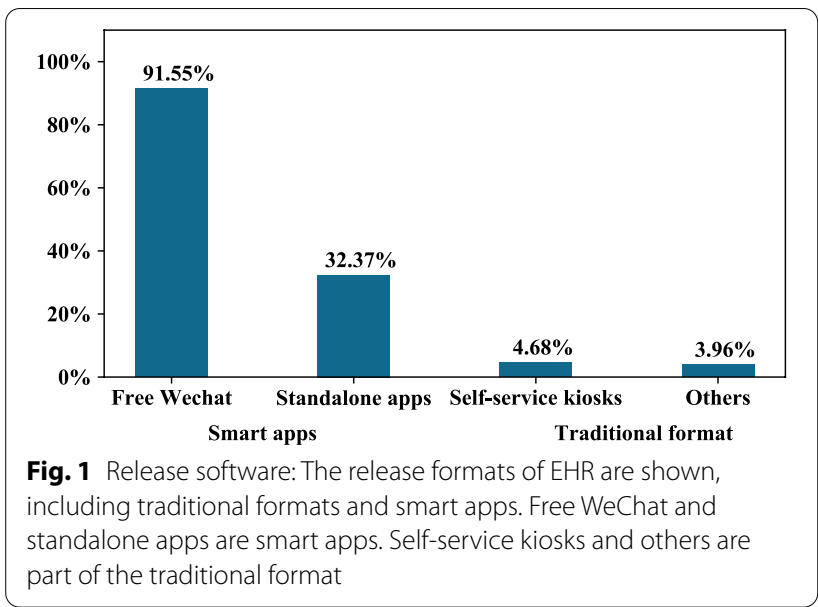

to inpatients only, and most hospitals released data to both outpatients and inpatients.

EHR data can be classified into two categories, objective and subjective. Objective data are those that could be generated directly by medical devices or reagents, which include lab reports, examination reports, prescriptions, and images; subjective data are those that are created by medical staff based on their professional knowledge or clinical experiences, which include discharge summary and diagnosis. Among all 1344 responding hospitals, only four hospitals released both objective and subjective EHR data to patients. The top four types of released EHR data (above 60\%) are lab reports, exam reports, prescriptions and $\mathrm{PE}$ data, which are all in the objective category, as shown in Fig. 2. Release times range from real-time to a delay of a few hours or days, according to hospitals' specific policies. Most hospitals validate data accuracy before releasing the information to patients.

\section{Field interview}

In addition, we field-interviewed 7 comprehensive tertiary hospitals, which were included in all 1344 responding hospitals, as supplementary data to the survey. Questions included: What is the doctors' reaction to patients' access to their EHR data? Does that truly help them improve quality or efficiency? Do patients feel more satisfied after hospitals do so? What is the cost-effectiveness for both hospitals and patients? Among those questions, cost-effectiveness was the chief concern for both the hospital and the patients.

For these 7 hospitals, we interviewed both CIOs and CEOs and collected their IT investment and cost savings via smart apps (for confidential purposes, we cannot list detailed data for each hospital). Then, we made a rough estimation of a normal-sized comprehensive tertiary hospital, with 2 million outpatient services, 80,000 inpatients and 3 billion RMB in revenue per year.

Hospital costs for EHR data release to patients via smart apps consist of multiple components, including IT construction \& operation maintenance, cloud storage, web security \& E-signature, EHR paper and image materials purchasing and printing. In spite of that, for the match of smart apps, hospitals have to invest more in system development, web infrastructure, security protection, and e-signature. The returns (or the cost savings) of EHR data release are from both sides, the hospitals and the patients.

Table 2 shows that if a normal-sized comprehensive hospital releases EHR data to patients via smart apps (i.e., goes paperless), it can potentially save the hospital 11.8 million RMB per year and save the patients 9.4 million RMB altogether. Although hospitals have to invest in IT construction and operation maintenance, web security, cloud storage, and purchase printing materials, altogether, one comprehensive tertiary hospital can save 18.82 million RMB on

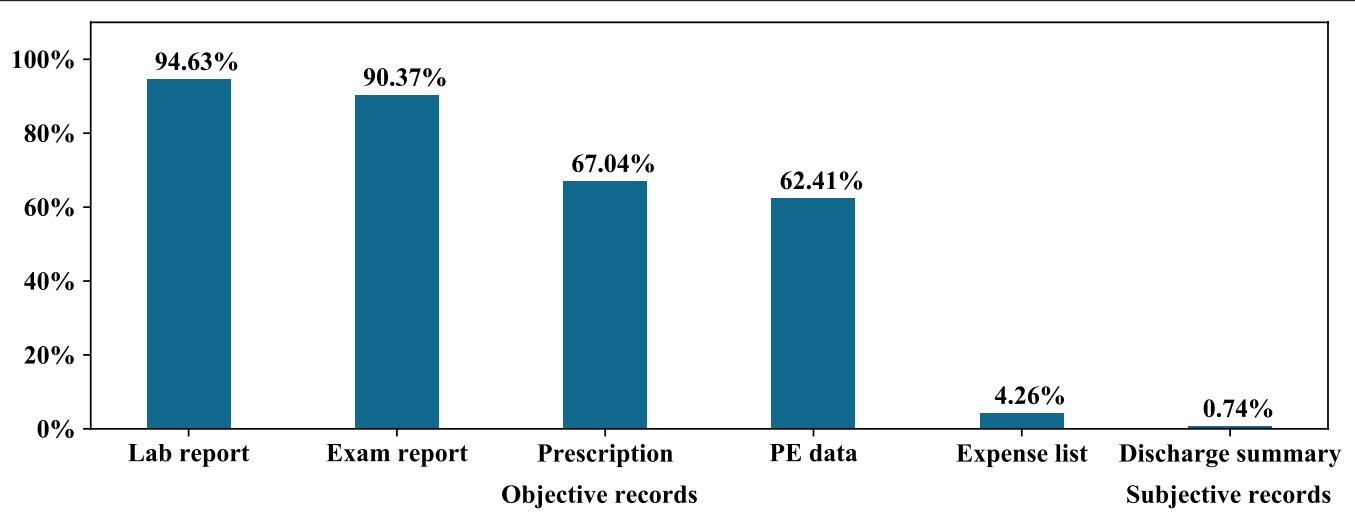

Fig. 2 Release content: Release content includes objective content and subjective content. Compared with the objective content, the subjective content is less released 
Table 2 Cost savings (million RMB)

\begin{tabular}{llll}
\hline Items & $\begin{array}{l}\text { IT investment } \\
\text { Hospital Cost/year }\end{array}$ & Cost saving & Patient/year \\
\cline { 3 - 4 } & 1.1 & Hospital/year & - \\
IT construction \& operation maintenance & 0.93 & - & - \\
Cloud storage & 0.35 & - & - \\
Web security \& E-signature & - & 4.2 & 1.1 \\
EHR paper \& printing & - & 7.6 & 8.3 \\
Images \& printing & 2.38 & 11.8 & 9.4 \\
Total & & & \\
\hline
\end{tabular}

both sides per year through this move. However, this estimation is not suitable for secondary and below hospitals.

\section{Discussion}

Through survey and field interviews, we can see many advantages of releasing EHR data to patients' smart apps, but there are also some obstacles that need long-term solutions. For example, the primary concern of hospitals is potential legal liabilities and conflicts since physicians' 'irregular' behaviours always lead to poor EHR data quality and may prevent hospitals from releasing those EHR data to patients. There are two possible causes why EHR data quality is not as good as expected. One is that physicians' documentation might be delayed, may use irregular wording or may be easily copied and pasted, which could become a huge threat to hospitals' willingness for EHR data release. In addition, doctors always need to make necessary adjustments and modifications to EHR content according to a patient's disease progression and condition, which could easily be misunderstood as errors and drawbacks by the patients, further arousing medical disputes or even doctors' defensive EHR writing.

Furthermore, patients' or their family members' willingness to know the reality of their health conditions is variable, especially for those who are diagnosed with sensitive diseases, such as infectious disease or cancer. Patients' family members may choose to tell white lies in consideration of their mental stress. Therefore, smart and smooth EHR data release could become a negative option or an honest mistake.

Third, hospital IT infrastructures and application situations are different from hospital to hospital, and many of the systems inside hospitals are silos, which may narrow down the data type and content; thus, the patients cannot obtain enough data that are needed for future use.

\section{Conclusions}

Leveraging data from a large survey and field interviews, we found that EHR data release in tertiary hospitals is better than that in secondary hospitals. More than half of the comprehensive tertiary hospitals and some of the secondary hospitals have already released EHR data to patients' smart apps, especially for outpatients and on objective content of EHR data. This act is believed to bring cost savings and efficiency gains to both the patients and the hospitals but is still considered spontaneous, without legal support and government regulation. The NHC is currently giving this issue much attention for the protection of patients' information security and may issue suitable policies for future regulation and application.

\section{Abbreviations}

NHC: National Health Commission of the People's Republic of China; EHR: Electronic health records; APP: Application; IT: Information Technology; PE: Physical Examination; CEO: Chief Executive Officer; ClO: Chief Information Officer.

\section{Acknowledgements}

This work was supported by grants from the National Institute of Hospital Administration, NHC, China. We thank our expert consensus panel for their assistance in conducting this research and data analysis.

\section{About this supplement}

This article has been published as part of BMC Medical Informatics and Decision Making Volume 21, Supplement 2 2021: Health Big Data and Artificial Intelligence. The full contents of the supplement are available at https:// bmcmedinformdecismak.biomedcentral.com/articles/supplements/volum e-21-supplement-2.

\section{Authors' contributions}

TS, FX and HL contributed to the research design, data acquisition and analysis. TS and FX contributed to manuscript writing. WZ participated in data interpretation and helped draft and revise the manuscript. All authors read and approved the final manuscript.

\section{Funding}

WZ, the corresponding author pays for the publication.

\section{Availability of data and materials}

The datasets generated and/or analysed during the current study are not publicly available because our data belong to the National Health Commission, and they do not agree to make it public.

\section{Ethics approval and consent to participate}

This study did not require ethics committee approval regarding compliance with animal/human ethics guidelines.

Consent for publication

Written informed consent for publication was obtained from all participants. 


\section{Competing interests}

The author(s) declare(s) that they have no competing interests.

Received: 4 February 2021 Accepted: 8 February 2021

Published: 30 July 2021

\section{References}

1. Vaishali Patel MPH, Christian Johnson MPH. Individuals' use of online medical records and technology for health needs. ONC Data Brief No. 40.1-17;2018

2. Shu T, Liu H, Goss FR, Yang W, Zhou L, Bates DW, Liang M. EHR adoption across China's tertiary hospitals: A cross-sectional observational study. International Journal of Medical Informatics, 83(2), 113-121;2014. https:// doi.org/10.1016/j.ijmedinf.2013.08.008.

3. Al Abdullah M, Al Bakri AA. Electronic health record system: adoption and influencing factors. Int J Entrepreneurship InnovManag. 2016;20(3-4):200-13.

4. Burke HB, Becher DA, Hoang A, Gimbel RW. The adoption of an electronic health record did not improve A1C values in Type 2 diabetes. J Innov Health informatics, 23(1), 144-144;2016. https://doi.org/10.14236/jhi. v23i1.144

5. Chauhan Z, Samarah M, Unertl KM, Jones MW.. Adoption of Electronic Dental Records: Examining the Influence of Practice Characteristics on Adoption in One State. Applied Clinical Informatics, 9(3), 635-645; 2018 https://doi.org/10.1055/s-0038-1667331.

6. Cohen MF. Impact of the HITECH financial incentives on EHR adoption in small, physician-owned practices. International Journal of Medical Informatics, 94, 143-154;2016. https://doi.org/10.1016/j.jijmedinf.2016.06.017.

7. Song Z, Guo F, Chen D Examination and management of EHR evidence qualification. Journal of Northwest University (Philosophy and Social Sciences Edition). 2015,45(03):93-99. https://doi.org/10.16152/j.cnki.xdxbs k.2015-03-014.

8. Junfeng $\mathrm{S}$, Qianqian Li, Jianxin Bi. Integrated management of EMR in cloud computing environment. Chin Hosp Manag. 2015;35(02):44-6.

9. LV Y, Shi $Q$, Zhang $H$, et al. Research progress in quality control of $E H R$ connotation. Chin J Public Health. 2014,30(12):1582-1583.

10. Yang JY, Qiubin GY, et al. A survey of named entity recognition and entity relationship extraction in HER. Acta Automatica Sinica. 2014;40(08):1537-62.

11. Yuling $\mathrm{G}$. On the protection of patients' privacy right in medical informatization - from the perspective of the application of EHR. Legal Forum. 2014;29(02):74-9.

12. Bayne LE. Big Data in Neonatal Health Care: Big Reach, Big Reward? Critical Care Nursing Clinics of North America, 30(4), 481; 2018. https://doi. org/10.1016/j.cnc.2018.07.005.
13. Cassavia N, Ciampi M, De Pietro G, Masciari E. Enhancing EHR Systems Interoperability by Big Data Techniques. In M. E. Renda, M. Bursa, A. Holzinger \& S. Khuri (Eds.), Information Technology in Bio- and Medical Informatics (Vol. 9832, pp. 34-48); 2016.

14. Chauhan R, Jangade R, Mudunuru VK. A Cloud Based Environment for Big Data Analytics in Healthcare. In A. Abraham, A. K. Cherukuri, A. M. Madureira \& A. K. Muda (Eds.), Proceedings of the Eighth International Conference on Soft Computing and Pattern Recognition (Vol. 614, pp. 315-321); 2018.

15. Nortey RN, Yue L, Agdedanu PR, Adjeisah M. IEEE Privacy Module for Distributed Electronic Health Records(EHR) Using the Blockchain; 2009.

16. Pant, D., Kumar, V., Kishore, J., Pal, R., \& leee. (2017). Healthcare Data Modeling in $\mathrm{R}$.

17. Salavati H, Sadeghi R, Gandomani TJ. leee A Robust Software Architecture Based on Distributed Systems in Big Data HealthCare;2017.

18. Wu PY, Cheng CW, Kaddi C, Venugopalan J, Hoffman R, Wang MD. Advanced big data analytics for -omic data and electronic health records: toward precision medicine. IEEE Trans Bio-med Eng;2016. https://doi. org/10.1109/tbme.2016.2573285.

19. Wu PY, Cheng CW, Kaddi CD, Venugopalan J, Hoffman R, Wang MD (2017) Omic and electronic health record big data analytics for precision medicine. IEEE Trans Biomed Eng 64(2): 263-273

20. Yu WD, Gottumukkala A, Senthailselvi DA, Maniraj P, Khonde T. leee Distributed Big Data Analytics in Service Computing; 2017.

21. Shu T, Liu H, Zhao W. Discussion on the revision of the grading evaluation standard of the functional application level of the EHR system. Chin J HospAdm. 2018;34(3):198-200.

22. Zhao $X$. The change from government information to government data. Inf Stud Theory Appl. 2017;40(04):1-9.

23. Zhang X, Wang W, Tang C. A study on the policies and regulations of data releaseing and privacy protection of Chinese and American governments. Inf Stud Theory Appl. 2016;39(01):38-43.

24. Liu N, Chen M. Research on methods and Strategies of medical data releaseing. Chin HospManag. 2016;39(01):38-43.

25. Jun L, Zhong L. From Obama medical care to trump medical care: the Enlightenment of American medical reform to China. Chin Health Econ. 2018;37(04):94.

\section{Publisher's Note}

Springer Nature remains neutral with regard to jurisdictional claims in published maps and institutional affiliations.
Ready to submit your research? Choose BMC and benefit from:

- fast, convenient online submission

- thorough peer review by experienced researchers in your field

- rapid publication on acceptance

- support for research data, including large and complex data types

- gold Open Access which fosters wider collaboration and increased citations

- maximum visibility for your research: over 100M website views per year

At BMC, research is always in progress.

Learn more biomedcentral.com/submissions 